\title{
GENDER AGREEMENT IN CHICHEWA*
}

\author{
Greville G. Corbett \\ University of Surrey
}

Alfred D. Mtenje

University College London

\begin{abstract}
Gender in Chichewa is described as a complete system. First the basic data on gender agreement are presented and it is shown how the available agreement markers correlate with the noun genders (and how the system has changed in the recent past). There follows a discussion of interesting phenomena which do not fit easily into the main gender system. Next structures involving conjoined noun phrases headed by nouns from various genders are analysed in detail. The rules required to account for the Chichewa system prove particularly complex; rules proposed for other Bantu languages do not cover all the Chichewa facts. The data are important for comparative work within Bantu and for typological claims which go beyond.
\end{abstract}

\section{Introduction}

In this paper we give an overall view of the gender system of Chichewa. We distinguish between the genders into which nouns are divided and the agreement markers used to agree with them, and we show that the relation between them is not straightforward. We also cover phenomena on the fringe of the gender system, such as nouns which do not fall completely into a single gender,

*Corbett's part of this research was supported by the Economic and Social Research Council (UK), grant reference number C00232218. This support is gratefully acknowledged. Mtenje wishes to thank the Association of Commonwealth Universities for a grant enabling him to undertake postgraduate study in Britain. We are also grateful to the following for their intuitions: Sam Mchombo, Lazarus Miti, Alice Mtenje, and Mike Zulu. Their judgements do not coincide with those of Mtenje for all examples, and we have concentrated on his idiolect, but having their reactions for comparison was most helpful. 
and we relate these data to more general typological claims. The most interesting problem is that of gender agreement with conjoined noun phrases (gender resolution). This question has been the subject of several studies on different Bantu languages. Chichewa is particularly instructive and we relate our findings both to work in Bantu and to relevant data outside.

The paper is structured as follows: after brief background notes (section 1), we outline the gender agreement system (section 2), then discuss problems at the margin of the system (section 3), before turning to the major problem, that of gender resolution (section 4).

\section{Background}

This study is essentially a description of the gender system of one native speaker of Chichewa (the second author) as spoken in Malawi in Central Africa. The dialect examined here corresponds fairly closely to the "Standard" dialect of Malawian Chichewa; it is one of the dialects of what is called "Chinyanja" in neighbouring countries like Zambia, Zimbabwe, and Mozambique. Since, for socio-political as well as linguistic reasons, the term "Chichewa" is used on1y in Malawi, we will continue in this paper to employ this name to refer to the Malawian dialect, as opposed to other terms (such as Chinyanja/Chichewa as used by some other authors, including Mapanje [forthcoming]).

Chichewa belongs to the Bantu group of languages of Africa; it is classified by Guthrie as N31B. Like many other Bantu languages, Chichewa is a tone language; lexical (and, in some cases, grammatical) contrasts may be signalled by variations in pitch levels. There are two level tones in Chichewa, high (H) and low (L). One may also find contour (gliding) tones which are obtained only as a combination of the two level tones. Thus, a low tone followed by a high tone on one syllable ( $\hat{\mathrm{LH}}$ ) yields a rising tone while the reverse sequence (HL) gives a falling tone.

Since our interest in this study is in the system of gender in Chichewa, we will ignore details of tone; examples will therefore be given without tone markings. Besides, none of the arguments given cructally hinges on tone. A detailed discussion and analysis of tone in Chichewa within an autosegmental model is available in Mtenfe [1986]. 
Another salient structural property which Chichewa shares with other Bantu languages is the division of nouns into genders, traditionally referred to as noun classes. Nouns can be assigned to genders in part on semantic grounds but phonological and morphological factors also play a part. It is this gender system which is the focus of our paper.

\section{Basic Agreement Facts}

We take as our starting point the clear account given by Watkins [1937]; data from Price [1943] have also proved useful, particularly as the basis for examples. First we present the forms acceptable to Mtenje within the descriptive scheme of Watkins, then we give the differences in detail between this idlolect and that described by Watkins; we also relate the description to the traditional Bantu schemes of noun classes. Watkins recognises ten classes (we sha11 call them genders) and a similar scheme is adopted by Mapanje [forthcoming]. We take agreement evidence to be crucial in setting up the genders. The following sentences illustrate the ten genders in turn, using subject agreement forms as a diagnostic; we label agreements simply as "ag":
(1) a. munthu a-ku-thamanga
person ag-pres-run
'the person is running'
b. anthu a-ku-thamanga
'the people are running'
people ag-pres-run

In this first gender, the subject agreement marker a is the same for singular and plural. However, object markers are distinct; (1c) and (1d) are continuations of $(1 a)$ and (1b) respectively:
c. ndi-ku-mu-ona
1st sg-pres-ag-see
'I see him/her'
d. ndi-ku-wa-ona 1st sg-pres-ag-see
'I see them'

The first gender is exceptional in having this coincidence of singular and plural for subject agreement, as well as in having considerable allomorphic variation for different agreeing elements. In the other genders, the singular and plural subject agreement forms are distinct, as in the following exam- 
ples (from genders 2, 3 and 4):
(2) a. mudzi u-ku-kula village ag-pres-grow
'the village is growing'
b. midzi $i-k u-k u l a$ villages ag-pres-grow
'the villages are growing'
'the leaf is rotting'
(3) a. tsamba li-ku-bvunda
leaf ag-pres-rot
'the leaves are rotting'
b. masamba a-ku-bvunda
leaves ag-pres-rot
(4) a. ulendo u-dza-tha journey ag-fut-end
'the journey will end'
b. maulendo a-dza-tha journeys ag-fut-end
'the Journeys w111 end'

In the fifth gender, number is again differentiated in the agreement markers, but not in the noun itself:
(5) a. njoka i-ku-gona snake ag-pres-lie flat
'the snake is lying flat'
b. njoka zi-ku-gona snakes ag-pres-lie flat
'the snakes are lying flat'

In the sixth gender, number is typically marked on noun and verb in the same way:
(6) a. chipatso chi-ku-bvunda
fruit ag-pres-rot
'the fruit is rotting'
b. zipatso zi-ku-bvunda
fruits ag-pres-rot
'the fruits are rotting'

This phenomenon, sometimes termed "alliterative concord", is often treated as the norm in Bantu languages, even a defining feature. When we view the Chichewa gender system as a whole, however, we see that while there is often some relation between the morphology of nouns and the agreements they take, the two by no means coincide. ${ }^{1}$ (The situation is not so different from Indo-

${ }^{1}$ Semantic factors clearly have a role in that most nouns denoting humans 
European languages like Latin or Russian.) The seventh gender also shows a1literative concord. It is a special gender in that it comprises mainly nouns formed from nouns of other genders. Original prefixes are retained, and a new prefix is added to give diminutive meaning. Thus besides the noun mwana/ana 'child/children' (gender 1), we find kamwana/tlana 'infant/infants':
(7) a. kamwana ka-li bwino
'the infant is wel1'
infant ag-be in good order
b. tiana $t i-l i$ bwino infants ag-be in good order
'the infants are well'

The remaining three genders are all to be distinguished from the genders we have discussed so far. They are the so-called locative genders. They each have one agreement form, not a singular-plural pair like the other genders. And there are very few nouns which are restricted to these genders. Gender 8 is used to show position (roughly 'at/on'):
(8) panyumba pa-ku-tentha
at house ag-pres-hot
'it is hot at the house'

Nyumba 'house' is an ordinary gender 5 noun. There are a few nouns, often body parts, which typically occur in this gender, such as pakhosi 'neck' and pakamwa 'mouth'; pa is felt to be the normal prefix and similarly pa the normal agreement marker. It is not, however, possible to add a second pa to ensure locative meaning (*papakhosi).

Gender 9 is for location within:

(9) munyumba mu-ku-tentha

'it is hot in the house'

in house ag-pres-hot

The final gender, number 10, can designate more general location:

belong to gender 1 . But phonological and morphological factors also play a part in gender assignment. For instance, it is generally the case that nouns whose initial prefixes have the palatal affricate ([C.]) belong to gender 6 . Similarly, most nominals with initial nasals belong to gender 5 , just as most nouns beginning with aspirated plosives are members of gender 3 . 
(10) kudambo ku-ku-nunkha 'it smells about the marsh'
about marsh ag-pres-sme11

The tenth gender also includes verbal nouns:

(11) kuthamanga ku-ma-pweteka 'running hurts'
running ag-habitual-hurt.

These last three genders are clearly different from the others and there might be some question as to whether they should be called genders at all. For the present, our purpose is to record the forms. For a convincing account of the reasons for special treatment of these genders in ChiBemba see Givón [1972:12-13, 28-34]; for a discussion of locatives in 0luLuyia, see Dalgish [1976].

We now bring together the data on Watkins' ten classes (as illustrated in the sentences above) and relate them to the traditional Meinhof numbering scheme. We thus follow Doke's recommendation [1935:64] of grouping singular and plurals together for studying an individual language, while also referring to the Meinhof numbering.

Table 1: Subject concord markers in Chichewa

\begin{tabular}{cccc} 
Watkins class & Common Bantu class & \multicolumn{2}{c}{ agreement markers } \\
singular & plural \\
1 & $1 / 2$ & $\mathrm{a}$ & $\mathrm{a}$ \\
2 & $3 / 4$ & $\mathrm{u}$ & $\mathrm{i}$ \\
3 & $5+11 / 6$ & $\mathrm{li}$ & $\mathrm{a}$ \\
4 & $14 / 6$ & $\mathrm{u}$ & $\mathrm{a}$ \\
5 & $9 / 10$ & $\mathrm{i}$ & $\mathrm{zi}$ \\
6 & $7 / 8$ & $\mathrm{chi}$ & $\mathrm{zi}$ \\
7 & $12 / 13$ & $\mathrm{ka}$ & $\mathrm{ti}$ \\
8 & 16 & $\mathrm{pa}$ & \\
9 & 18 & $\mathrm{mu}$ & \\
10 & $15+17$ & $\mathrm{ku}$ &
\end{tabular}

The Watkins numbers are straightforward; the concords are illustrated in sentences (1)-(10), gender 10 also being Illustrated in sentence (11). The tra- 
ditional Bantuist numbering separates singular and plural, hence Watkins' class 1 would be class 1 singular and class 2 plural. This scheme has advantages for historical and comparative work. Nouns of class 11 (singular) appear to have joined class 5, and the two functions of Watkins' class 10 were originally fulfilled by two different classes.

In Table 1 we have given only subject agreement markers, rather than a large table with all agreement markers listed separately (for a particularly Impressive example of this genre see Laws [1885]). The point is that the different agreement markers (for different agreeing elements) almost all involve automatic alternations, ${ }^{2}$ and listing these variants would obscure rather than clarify the issues we wish to address. The gender where alternations tend to be irregular is the first, as we saw in sentences (1c) and (1d). Besides the main allomorph $\mathrm{a}$ and the allomorph $\mathrm{mu}$ for object agreement, there is another allomorph $u$ found, for example, with certain pronouns and with the perfect tense.

We now turn to the differences between Mtenje's idiolect and that described by Watkins, which are as follows:

1. Watkins gives $\beta a$ (orthographic $\hat{w a} ; \hat{w}$ is an unrounded bilabial glide) as the plural for genders 1,3, and 4. Mtenje has $\hat{w a}$ as a more marked alternative to $a$ in all three cases.

2. Watkins has bu as an alternative to $u$ for singular agreement with gender 4. He states that bu is used more frequently by older people [1937:34]. This alternative is not used by Mtenje, but only $u$.

3. For singular object agreement with gender 4, besides the alternative bu as for subject concord, Watkins gives only $u$, while for singular object concord with gender 2 he gives $(w) u$. In fact the appearance or not of $W$ is a phonetic problem; there is variability as to when $W$ is possible, but $u$ and $w u$ cannot constitute a minimal pair. Hence there are no grounds for differentiating between the singular concords of the second and fourth genders, since when $w$ is possible in one it will also be possible in the other.

${ }^{2}$ The morphological processes involved are described with relation to specific examples in footnotes 4,9 , and 10 below. 
4. For the plural concord of gender 6 , Watkins has $v i$ while Mtenje has $\mathrm{zi}$. $\mathrm{Vi}$ is maintained in some dialects, particularly in the northern part of the Chichewa speaking area, but for Mtenje the plural concords of genders 5 and 6 are identical.

5. For the plural concord of gender 7 Watkins has tu while Mtenje uses ti.

It is also worth recording a difference as compared to the table at the end of Price [1943], which links to point 1 above. For the perfect tense prefix for the plural of gender 1, Price gives wa, while for the plurals of 3 and 4, he gives $a$. This is probably just an error. For Mtenje the unmarked form for all three is $a$, while $\hat{w a}$ Is an alternative; wa is not possible for any of the three.

If we now look back to Table 1, we can claim that the three plural markers a are indeed identical. Their allomorphs for the different agreeing elements have identical distribution (recall, however, that this is not the case for the singular a ). Similarly the two singular markers $u$ are identical, as are the plural markers $z i$. We can therefore redraw Table 1 to give a more accurate picture of the gender system of ChIchewa, by including agreement markers (or target gender forms) once only, and by representing sets of nouns taking identical agreements (controller genders) by lines drawn linking the relevant agreements:

Table 2: The gender system of Chichewa

$\begin{array}{ll}\text { singular agreement } & \text { plural agreement } \\ \text { markers } & \text { markers }\end{array}$

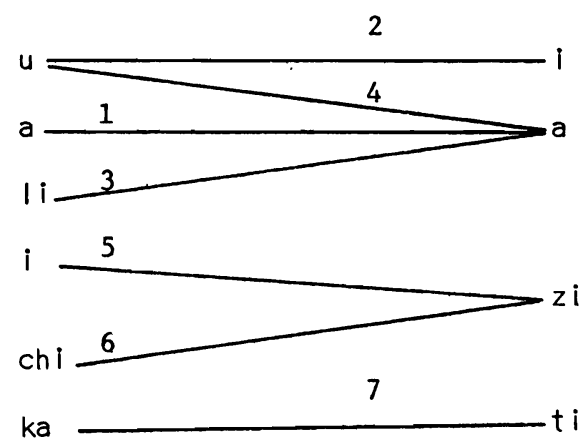


The numbers of course represent the genders according to Watkins' scheme. It is interesting to note that there are seven genders (we omit genders 8-10 here since they are outside the singular-plural opposition), though there are not seven distinct agreement forms in either number. There are in fact six singular forms and four plural forms. This pattern is in accord with Greenberg's [1963:112] Universal number 37: "A language never has more gender categories in nonsingular numbers than in the singular." The relation between the singular and plural forms is also of interest; given the concord taken by a noun in the singular, one cannot determine unambiguously the form it takes in the plural; similarly, given the plural, the singular cannot be uniquely determined. Such systems have been termed "crossed systems" [Heine 1982:197]. The appearance of this complex system is quite recent; as long as the singular agreements of gender 4 were distinct from those of gender 2, the system was not crossed. Given the singular agreement form, the plural could be predicted (though not vice versa). Heine calls systems like this earlier one "paired", though we would prefer the term "convergent". If we postulate an even earlier system in which the Common Bantu classes given in Table 1 had distinct agreement forms, then the system was even simpler in the sense there was a clearer matching of singular and plural agreement forms (though conversely it was more complex in the sense that there were more actual agreement markers).

\section{Marginal Gender Phenomena}

Having described the core of the gender system, we now turn to two problems: the first concerns nouns whose semantics and morphology are in conflict and the second is the problem of agreement in gender when there is no noun as head of the noun phrase controlling the agreement. (neutral agreement).

\subsection{Semantic agreement. The vast majority of nouns belong to a particular} gender and consistently take all the expected agreements. However, as is normally the case in gender systems, there is a small number of nouns which are not completely consistent. These are nouns for which the different principles of gender assignment come into conflict. ${ }^{3}$ There is a semantic principle ac-

\footnotetext{
${ }^{3}$ There are also instances in which nouns do not take the expected number
} 
cording to which nouns denoting humans are in gender 1 . And, as mentioned earlier, there is a morphological principle which determines the gender of a noun according to the prefixes it takes. Nouns which take no prefix in either singular or plural (and which therefore do not differentiate the numbers) normally belong in gender 5. There are a few nouns which denote humans (and so would be expected to be in gender 1), but which have the morphological form of gender 5. In Chichewa these normally take gender 5 agreements. Similarly, there are nouns denoting humans with. the prefixes chi-/zi- (the morphological form of gender 6) which normally take gender 6 agreements; in addition there are diminutives formed from nouns denoting humans which normally take the agreements of gender 7 .

agreement. Singular nouns denoting humans may take plural agreement, which indicates respect:
(i) bambo a-ku-yenda
'father is walking'
father ag-pres-walk

Bambo belongs to the first gender and so the $a$ is ambiguous; object agreement (wa) is unambiguously plural:
(ii) ndi-ku-wa-ona
1st sg-pres-ag-see
'I see him' (1iterally 'them')

The singular object marker $\mathrm{mu}$ would be grossly impolite. In fact all agreements will be plural:

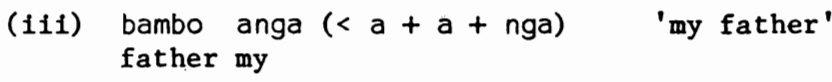

Again the singular wanga $(<u+a+n g a)$ would be inappropriate. of course, the use of the plural for politeness is a widespread phenomenon in Bantu, in Dravidian languages, and in Indo-European. What is particularly interesting here is that plural agreement is usual for all agreement targets, including the nominal predicate:

\section{(iv) bambo ndi aphunzitsl \\ father is teachers \\ 'father is a teacher'}

The use of the singular (mphunzitsi) would be a bald statement of fact, while (iv) identifies with father and is polite. The singular in (iv) is, however, less bad than in (iii). Note that the copula ndi does not inflect for number. The interest of (iv) is the plural nominal predicate as a politeness marker; the nominal predicate thus shows syntactic agreement with the subject, a phenomenon which Comrie [1975:410-412] in his survey of different predicate types, found extremely rare. 
Let us begin with the diminutives. Kamwana is a small child or infant. It takes agreements of gender 7:

kamwana ko-kongola ka-ku-gona

small child ag-pretty ag-pres-sleep

'the pretty small child is sleeping'4

Gender 1 agreements are ungrammatical:

*kamwana a-kongola a-ku-gona

small child ag-pretty ag-pres-sleep

'the pretty small child is sleeping'

Similarly with the relative pronoun:

$$
\begin{aligned}
& \text { kamwana ka-mene ka-ku-gona } \\
& \text { *kamwana a-mene a-ku-gona } \\
& \text { small child ag-who ag-pres-sleep } \\
& \text { 'the small child who is sleeping' }
\end{aligned}
$$

Subject pronouns are normally dropped; however, the form of emphatic pronouns, and of the subject agreement marker when no pronoun is included, are both norma11y of gender 7. Yet gender 1 agreements are also possible when sufficient1y separated from the noun:

${ }^{4}$ The form $k 0$ on kokongola is derived as follows. The initial stage is the attachment of the infinitive prefix $\mathrm{ku}$ (which is justified by the fact that it appears on the surface in the case of monosyllabic roots). Then the adjectival prefix $a$ and the agreement marker ka are attached:

$\begin{array}{lll}\mathrm{ka}+\mathrm{a} & +\quad \begin{array}{l}\text { ku } \\ \text { ag } \\ \text { prefix }\end{array} & \begin{array}{l}\text { kongola } \\ \text { verb root }\end{array}\end{array}$

Vowel coalescence reduces the identical vowel sequence $a+a$ to $a$ and the resulting structure $k a+k u$ undergoes a regular morpheme fusion rule which changes $a+k u$ into $o$ if the verb is not monosyllabic, yielding the required surface form kokongola. For details of the (morpho-) phonological rules referred to here, see Mtenje [1986; forthcoming]. Note that, for simplicity, we do not separate the final vowel from the stem throughout. 
(15) kamwana ka-mene ka-ma-gona mu-nyumba umu ka-mene ka-ma-pita small child ag-who ag-habit-sleep in house this ag-who ag-habit-go $k u$ sukulu ku London, mai ake a-ma- $\left\{\begin{array}{l}k a \\ m u\end{array}\right\}$-konda $\left\{\begin{array}{l}i k o(k o) \\ i y e(k o)\end{array}\right\}$ to school in London, mother his ag-habit-ag-love him

'the small boy who sleeps in this house who goes to school in London, his mother loves him'

In (15), ka and iko (which has the optional extension ko ) show agreement as for gender 7, while $\mathrm{mu}$ and iye(yo) are gender 1 forms. A similar effect can be observed in the plural (we change one of the nouns to avoid ambiguity in the agreement markers):

tiana ti-mene ti-ma-gona mu-nyumba umu ti-mene ti-ma-pita small children ag-who ag-habit-sleep in-house this ag-who ag-habit-go ku sukulu ku London, galu wa-wo $a-m a-\left\{\begin{array}{l}+i \\ w a\end{array}\right\}$-konda $\left\{\begin{array}{l}i+o(t o) \\ i \text { wo(wo) }\end{array}\right\}$ to school in London, dog ag-their ag-habit-ag-love them

'the small children who sleep in this house who go to school in London, their dog loves them'

Again the emphatic pronoun and the object agreement marker can be of gender 7 (syntactic) or of gender 1 (semantic), provided they are sufficiently far from the noun.

When we substitute the word chitsilu 'fool' (morphologically gender 6), then the switch to semantic agreement is not possible in an example similar to (15):

chitsilu chi-mene chi-ma-gona mu-nyumba umu chi-mene chi-ma-pita fool ag-who ag-habit-sleep in-house this ag-who ag-habit-go ku sukulu ku London, galu wa-ke a-ma- $\left\{\begin{array}{c}\star_{m u} \\ c h i\end{array}\right\}$-konda $\left\{\begin{array}{l}* i y e(y o) \\ i c h o(c h o)\end{array}\right\}$ to school in London, dog ag-his ag-habit-ag-love him

'the fool who sleeps in this house who goes to school in London, his dog loves him'

However, when the pronoun is yet further removed from the noun, semantic agreement becomes a possible alternative: 
(18) chitsilu chi-mene chi-ma-gona mu-nyumba umu chi-mene chi-ma-pita fool ag-who ag-habit-sleep in-house this ag-who ag-habit-go

ku sukulu ku London, galu wa-ke a-ma-chi-konda ndipo mai a-ke to school in London, dog ag-his ag-habit-ag-love and mother ag-his a-ma-bvomera-di kuti a-na- $\left\{\begin{array}{l}m u \\ c h i\end{array}\right\}$-ona $\left\{\begin{array}{l}i \text { ye(yo) } \\ i c h o(c h o)\end{array}\right\}\left\{\begin{array}{l}a \\ c h i\end{array}\right\}$-ku-yenda ag-habit-agree-indeed that ag-past-ag-see him ag-pres-walk

ndi galu yo

with dog that

'the fool who sleeps in this house who goes to school in London, his dog loves him and indeed his mother agrees that she saw him walking his dog'

Not surprisingly, the switch to semantic agreement in longer sentences is also possible with kamwana 'infant'. With a noun like nkhalamba 'old person', the switch from gender 5 to gender 1 is acceptable in sentences like (18), and is marginally possible in sentences like (15), but the result in the latter is less good than with kamwana. Thus the switch is easiest with kamwana (gender 7), then with nkhalamba (gender 5), and most difficult with chitsilu (gender 6).

These examples provide interesting support for the claim of the Agreement Hierarchy. This hierarchy, for which see Corbett [1979, 1983a:8-41, forthcoming] and Cornish [1986:203-213], consists of four basic positions:

attributive modifier $<$ predicate $<\underset{\substack{\text { relative } \\ \text { pronoun }}}{\substack{\text { personal } \\ \text { pronoun }}}$

The claim made is as follows:

For any controller that permits alternative agreement forms, as we move rightwards along the Agreement Hierarchy, the likelihood of agreement forms with greater semantic justification will increase monotonically.

The Chichewa data support this claim. Though semantic agreement (gender 1 agreement with nouns in other genders which denote humans) is only a marginal phenomenon in Chichewa, the one position where it is possible is in the (emphatic) personal pronoun (and of course in agreements dependent on it or on a dropped pronoun). Though the hierarchy was postulated on the basis of evidence from a range of languages, most of the data were from Indo-European; 
thus data from Bantu are of special interest. Furthermore, it was claimed that within any one position on the hierarchy, the chofce of agreement form may be influenced by "real" distance, the degree of separation of the target from its controller measured in words. And indeed, we have seen convincing evidence that semantic agreement becomes more likely the further the pronoun is separated from the controlling noun.

3.2. Neutral agreement. All gender systems require a strategy for agreement with elements which do not carry gender and number features in the normal way. Such elements vary from infinitives to interfections. There are two strategies: either one of the normal agreement forms is used (often the third singular neuter), or there may be a special form solely for this purpose [Corbett 1980]; even when a normal form is used it can usually be distinguished by some syntactic means.

In Chichewa, the situation is particularly interesting in that the equivalent of the infinitive is marked by a special prefix $\mathrm{ku}$ and also takes $\mathrm{ku}$ as an agreement marker, as illustrated in example (11) above; there is a speclal gender (gender 10) which infinitives share with locatives. There is still the question of interjections. Consider the following example:

$$
\begin{aligned}
& \text { 'aaa' a-na-mv-eka } \\
& \text { 'aaa' ag-past-hear-passive }
\end{aligned}
$$$$
\text { 'an "aaah" was heard" }
$$

We must ask what form of agreement the $a$ is. It is not a simple alliterative agreement as the next examples prove:

'ooo' a-na-mv-eka
'ooo' ag-past-hear-passive

'an "oooh" was heard'

$$
\begin{aligned}
& \text { 'mayo' a-na-mv-eka } \\
& \text { crying-sound ag-past-hear-passive }
\end{aligned}
$$

'a crying sound was heard'

To determine which a marker is involved we should consider object agreement (cf. (1c) and (1d)):

$$
\begin{aligned}
& \text { a-na-mu-mva 'mayo' } \\
& \text { ag-past-ag-hear crying sound }
\end{aligned}
$$

'he heard a crying sound'

In this example the initial a represents subject agreement; mu is the form 
of interest; it is the object agreement marker which agrees with, or, more accurately, shows the failure of agreement with, the element in object position, mayo. Note that in all these examples the form $\mathrm{ku}$, which is found with infinitives, is unacceptable. The last example demonstrates that the acceptable form is in fact the singular of gender 1; this is surprising, since the first gender is associated with humans (though not exclusively). The syntactic effect with such neutral agreement mentioned earlier, is that conjoining forms which take neutral agreement usually does not produce a plural. Indeed, the same effect is observed in Chichewa:

$$
\begin{aligned}
& \text { 'mayo' ndi 'aaa' wa-ke ti-na-mu-mva kutali } \\
& \text { crying-sound and 'aaah' ag-his ag-past-ag-hear far away } \\
& \text { 'we heard his crying sound and "aaah" far away' }
\end{aligned}
$$

The wa ( $u+a)$ of wake is a gender 1 singular marker; $t i$ is first plural subjective concord; the $\mathrm{mu}$ is again gender 1 singular objective concord. Thus elements which are outside the gender system take gender 1 singular agreement as the neutral agreement form; this remains the only acceptable form even when such elements are conjoined. Chichewa (and, we assume, various other Bantu languages) is interesting typologically in this respect, since there is a special agreement form for infinitives, but this form does not function as the neutral agreement form. 5 Whereas, from comparisons beyond Bantu, we might have expected elements outside the gender system to take the same agreements as infinitives, the role of neutral agreement marker is, rather surprisingly, filled by the marker for the singular of gender 1 .

${ }^{5}$ This construction should be distinguished from that in which there is an implied locative such that the noun phrases present in surface structure do not control verb agreement, as in the following:

(i) ku-li mphepo ndi mitambo 'there is wind and clouds' ag-be wind and clouds

$\mathrm{Ku}$ is the gender 10 locative marker, indicating general location. In suitable contexts, similar examples with pa and $m u$ are also possible. The word order is fixed as in ( 1 ); noun phrases which precede the verb must control subject-verb agreement. 


\section{Gender Resolution}

Gender resolution is one of the most interesting areas of Bantu syntax; given the relatively high number of genders it is natural to ask what happens in conjoined structures. Provided agreement is with all the conjuncts, then rules are required to specify both number and gender. The number rule is straightforward (there is no complication of the dual number, for example): conjoined noun phrases take plural agreements. (However, a restriction will be imposed on this rule at the end of section 4.1.) 6

Gender is, of course, much more complex. Interest in this area was stimulated by the important work of Givón [1970; 1972:80-93]. Givón coined the term "gender resolution", though it is important to realise that gender reso-

${ }^{6}$ Note too that resolution does not always apply; the usual alternative is for agreement to be controlled by the nearest conjunct (see Brauner [1979: 425], Corbett [1983b:179-182], and Bokamba [1985:44-45]). Resolution or lack of it is an instance of semantic versus syntactic agreement, resolution representing semantic agreement. Again Chichewa provides data to support the Agreement Hierarchy (cf. section 3.1). In attributive position, resolution is not possible. Both conjuncts must take identical modifiers:

(1) Ialanje la-bwino ndi tsamba la-bwino 'a good orange and a good leaf' orange ag-good and leaf ag-good

The adjectives (labwino < $i+a+b w i n o$ ) are singular. If either is omitted then the referent of the noun phrase without the adjective is not understood to be "good". The more important point for our purposes is that the plural (resolved form) is ungrammatical:

(ii) *lalanje ndi tsamba za-bwino

'a good orange and leaf' orange and leaf ag-good

Placing the plural adjective after lalanje is equally bad, as is the use of the gender 3 plural form a-bwino in place of za-bwino. However, in all other positions on the Agreement Hierarchy, plural forms are normal:

(iii) lalanje ndi tsamba zi-li apo orange and leaf ag-be there

'the orange and leaf are there'

(iv) Lalanje ndi tsamba zi-mene zi-li apo za-gul-idwa ku msika. orange and leaf ag-which ag-be there ag-buy-passive at market

Izi ndi zakudya za-ana.

pronoun-ag be plural-food ag-children

'The orange and leaf which are there were bought at the market. They are foodstuffs for children.' 
lution rules may operate even when there is no "clash"; as we shall see below, if all conjuncts are headed by nouns of the same gender it does not follow that agreement will be in that gender. Givón's work has led to several publications on the problem, and we too will use his account as the framework for our analysis. Givón analyses Luganda and ChiBemba. Voeltz [1971] considers problematic data in Xhosa, where gender resolution is more restricted than in Luganda and ChiBemba. Roberts and Wolontis [1974] modify and extend the rules proposed by Voeltz, and also widen the range of languages to include Tswana and Zulu. Brauner [1979] gives examples of gender resolution (mainly for nonhuman conjuncts but also cases of human and non-human conjoined) from written Swahili sources. The brief description of gender resolution in Mateene [1980: 332-333] suggests that Nyanga is broadly similar to ChiBemba. Givón's data were considered in a general typology of resolution rules in Corbett [1983b]. Finally Bokamba [1985] extends the languages considered to include Dzamba, Likila, and Lingala.

Given the different patterns of gender resolution found in the languages investigated to date there is clearly some challenging comparative and typological work to be done. As preparation for this we require data on as many different languages as possible. Chichewa appears to be an interesting case, being more restrictive than ChiBemba but less so than Xhosa. In some cases the judgements are not clear-cut; various combinations cause problems. And there is variation between speakers in the acceptability of some sentences. In view of the need for comparative data, we have concentrated on trying to describe the system of one speaker (Mtenje) as accurately as possible. It is perhaps worth pointing out that for those examples for which we have the judgements of three speakers, Mtenje's judgement is "average", in that he usually accepts more examples involving gender resolution than one of our three main informants and fewer than the third. In this description we include

\footnotetext{
$\mathrm{Izi}$ is an emphatic personal pronoun, consisting of $i$ (root) $+z i$ (plural agreement marker) $+i$ (proximate marker); $i+i$ becomes $i$ by vowel coalescence. Thus, semantic (resolved, plural) agreement is found in the predicate and in the positions to the right on the Agreement Hierarchy (the relative and personal pronouns), but not in attributive position. This is fully in accord with its predictions.
} 
problems which are often disregarded in accounts of gender, such as the agreements used with conjoined infinitive phrases.

We begin with Givón's scheme of rules, which may be reformulated as follows:

1. If all the conjuncts are semantically [thuman], the plural of gender 1 ( $a$ in Chichewa) will be used.

2. If none of the conjuncts is semantically [+human], the plural of gender 6 ( $\mathrm{zi}$ in Chichewa) will be used.

3. If the conjuncts are semantically mixed, the comitative construction is preferable; if gender resolution is forced, the form will be as in rule 2 .

It is worth pointing out that similar rules (but without any mention of difficulty in conjoining animates with inanimates) were proposed by Horton [1949: 189] for Luvale. The important thing about these rules is that they have a semantic basis: it is the noun's meaning rather than its grammatical gender which counts. For ease of exposition we shall consider in turn examples in which none of the conjuncts denotes a human (section 4.1), those where only humans are involved (section 4.2), and those in which the conjuncts are semantically mixed (section 4.3); finally we summarise the rules for gender resolution (section 4.4$)$.

4.1. No conjuncts denoting humans. When none of the conjuncts denotes a human, we would expect the agreement marker to be $z i$ (traditional class 8 ). Since this form serves as the plural of gender 5 as well as of gender 6 in Chichewa, it would be reasonable to suppose that it would be, if anything, more generally used for gender resolution in Chichewa than in ChiBemba. However, though $\mathrm{zi}$ is indeed the main form for agreement with conjoined noun phrases denoting non-humans, there are several complications, as we shall see below. Let us consider first the straightforward cases:

(24) ukonde ndi chipatso zi-ku-bvunda

$4 \mathrm{sg} \quad 6 \mathrm{sg}$ ag-pres-rot

net and fruit are rotting

(25) mtengo ndi masamba zi-ku-kula

$\begin{array}{lll}2 \mathrm{sg} & 3 \mathrm{p} 1 & \text { ag-pres-grow } \\ \text { tree and leaves are growing }\end{array}$ 
malalanje ndi zikuni zi-ku-bvunda

$3 \mathrm{p} 1 \quad 6 \mathrm{p} 1 \quad$ ag-pres-rot

oranges and pieces of wood are rotting

In each of these there is a clash of genders. But this is certainly not a requirement for gender resolution, resulting in the use of $z i$. In the next example we have two nouns from the second gender, but $z i$ is still the required form:

mpeni ndi mphika zi-ku-sowa
2 sg $2 \mathrm{sg}$ ag-pres-missing
knife and pot are missing

The plural of gender 2 (*ikusowa) is quite unacceptable. Similarly with two nouns from gender 3 :

$$
\begin{aligned}
& \text { lalanje ndi tsamba zi-ku-bvunda } \\
& 3 \mathrm{sg} \text { a } 3 \mathrm{sg} \text { ag-pres-rot } \\
& \text { orange and leaf are rotting }
\end{aligned}
$$

The plural of gender 3 (*akubvunda) is not possible. There are thus good grounds for the claim that non-human conjuncts require the $\mathrm{zi}$ form. Not all combinations are so readily accepted. There was some hesitation over the following, but $z i$ was the only possible form:

(29) munda, ng'ombe $\begin{array}{ll}2 \mathrm{sg} & 5 \mathrm{sg} \text { (or } \mathrm{p} 1 \text { ) } \\ \text { garden, cow }\end{array}$ ndi khasu $z i-1 i$ uko

$$
3 \text { sg ag-be }
$$

and hoe are there

There was also considerable uncertainty when a diminutive was included, whether singular or plural:
(30)
(?) $4 \mathrm{sg}$ net
ukonde ndi
kakhasu
$z i-1 i$ uko
ag-be
7 sg and little hoe are there
(31) (?) ukonde ndi timakasu zi-li uko
$4 \mathrm{sg}$
net
$7 \mathrm{p} 1$
ag-be
and little hoes
are there

Though these combinations were less readily accepted than those given earlier, $\mathrm{zi}$ was still the only possible form. We suggest the following reason for the difficulty with (30) and (31). The overall scheme of the resolution rules 
is semantic (based on the feature [t/-human]). However, gender 7 has the closest correlation to semantics, its members being diminutives. It is the ignoring of this semantic feature in the agreement in (30) and (31) which gives the problem.

So far we have consldered combinations including at least one singular conjunct. When a11 confuncts are plural, the picture is more complex:

$$
\begin{aligned}
& \text { mipeni ndi miphika }\left\{\begin{array}{r}
i \\
z i
\end{array}\right\}^{-k u-s o w a} \\
& 2 \mathrm{p} 1 \quad 2 \mathrm{p} 1 \quad \text { ag-pres-missing } \\
& \text { knives and pots are missing }
\end{aligned}
$$

Both $i$, the agreement form for the plural of gender 2, and the zi form are acceptable. With gender 3, however, $a$, the agreement form for the plural of 3, seems normal, while $z i$ is less good:

$$
\begin{array}{lcc}
\text { malalanje ndi masamba } & \left\{\begin{array}{c}
a \\
? z i
\end{array}\right\}^{-k u-b v u n d a} \\
3 \mathrm{pl} & 3 \mathrm{p} 1 & \text { ag-pres-rot } \\
\text { oranges and leaves } & \text { are rotting }
\end{array}
$$

With gender $4, \mathrm{zi}$ is less good again:

(34) maukonde ndi mauta $\left\{\begin{array}{c}a \\ \text { ?? } i\end{array}\right\}^{-1 i \text { uko }}$

$\begin{array}{lll}4 \mathrm{p} 1 & 4 \mathrm{p} 1 & \text { ag-be } \\ \text { nets } & \text { and bows } & \text { are }\end{array}$

There are two hypotheses which would fit these data:

1. If plural nouns of the same gender are conjoined they take the plural agreement form for that gender.

This hypothesis is based on the gender of the nouns (the controller gender); it covers, for example, a sentence in which two gender 3 nouns are conjoined. The second hypothesis refers not to the gender of the nouns but to the agreement form (the target gender):

2. If plural nouns which would take the same plural agreement form are conjoined, then that form will be used.

(In either case zi- will be an alternative with varying degrees of acceptability.) To choose between the two hypotheses, we conjoin plural nouns of 
genders 3 and 4, which both have a as the plural marker. The second hypothesis predicts that a will be used, while the first makes no prediction (and so we would expect the regular form $z i$ ):

$$
\begin{array}{lcc}
\text { malalanje ndi maukonde } & \left\{\begin{array}{c}
\mathrm{a} \\
*_{\mathrm{z}} i
\end{array}\right\}^{-1 i} \text { uko } \\
3 \mathrm{pl} & 4 \mathrm{p} 1 & \text { ag-be } \\
\text { oranges and nets } & \text { are }
\end{array}
$$

This demonstrates that the second hypothesis is correct: when plural nouns which take the same agreement form (target gender form) are conjoined, that form will be used ( $z i$ may be an alternative). We can confirm this view by considering non-humans in gender 1. First an example with two nouns of that type:

$$
\begin{aligned}
& \text { amphaka ndi agalu }\left\{\begin{array}{c}
a \\
*_{z i}
\end{array}\right\}^{-k u-t h a m a n g a} \\
& 1 \mathrm{p} 1 \quad 1 \mathrm{p} 1 \text { ag-pres-run } \\
& \text { cats and dogs are running }
\end{aligned}
$$

Then a non-human from gender 1 together with a plural noun from gender 3 (which would also take a ):

(37) amphaka ndi malalanje $\left\{*_{z i} i\right\}^{-1 i}$ uko
$1 \mathrm{p} 1$
cats
$3 \mathrm{p} 1$
and oranges
ag-be
are there

Note that when animate class 1 nouns are conjoined, as in (36), * $z i$ was not accepted. With the few inanimates, $\mathrm{zl}$ was not excluded:
akatundu
ndi akabudula
$\left\{\begin{array}{r}a \\ ? z i\end{array}\right\}^{-k u-s o w a}$
$1 \mathrm{p} 1$
$1 \mathrm{p} 1$
the pleces and
of baggage

$$
\text { ag-pres-missing }
$$$$
\text { are missing }
$$
of shorts

Gender 5 has the added complication that the noun does not mark number. For this reason we include modiflers. Not surprisingly, all possibilities, singular and plural, take $z l$, since the general rule and the spectal rule for plurals both predict the $z i$ form: 
(39) mvuu i-modzi ndi njobvu i-modzi zi-ku-meny-ana

$5 \mathrm{sg}$ ag-one $5 \mathrm{sg}$ ag-one ag-pres-hit-recip

'a hippo and an elephant are fighting'

(40) mvuu $i-\bmod z i$ ndl njobvu zl-tatu zi-ku-meny-ana

$5 \mathrm{sg}$ ag-one $\quad 5 \mathrm{pl}$ ag-three ag-pres-hit-reclp

'a hippo and three elephants are fighting'

(41) mvuu zi-tatu ndi njobvu i-modzi zi-ku-meny-ana

5 pl ag-three 588 ag-one ag-pres-hit-recip

'three hippos and an elephant are fighting'

(42) mvuu zl-tatu ndl njobvu zi-tatu zl-ku-meny-ana

5 pl ag-three $\quad 5$ pl ag-three ag-pres-hit-reclp

'three hippos and three elephants are fighting'

We must also consider confoined plurals from the diminutive gender:

$\begin{array}{lcc}\text { timipeni ndi timiphika } & \left\{\begin{array}{c}t i \\ ? z i\end{array}\right\}^{-k u-s o w a} \\ 7 \mathrm{pl} & \begin{array}{l}7 \mathrm{pl} \\ \text { small knives and small pots }\end{array} & \text { are missing }\end{array}$

This confirms our hypothesis: each noun individually would take $t i$, and this is the preferred form when the nouns are conjoined.

When the conjoined noun phrases are headed by plural nouns which would require different agreement forms, then $z \mid$ is assigned by the usual rule:

(44) maukonde ndi mipenl zl-li uko
$4 \mathrm{p} 1$
2 pl ag-be
nets
and knives are there

Let us now consider the implications of the data in this section. We took as a working hypothesis the suggestion (from analyses of other Bantu languages) that any example all of whose conjuncts denote non-humans would take the agreement $\mathrm{zl}$. The situation in Chichewa turns out to be considerably more complex than that. There are cases where $z l$ is not possible or is not the preferred form. The most consistent and also the most interesting cases are those involving plural confuncts: If each individually would take the same target gender form, then this will be preferred ( $\mathrm{zl}$ may also be pos- 
sible).

These data recall the well-known analysis of Xhosa by Voeltz [1971]. Agreement with conjolned noun phrases is highly restricted in Xhosa, but is possible if plural noun phrases require phonologically identical markers. Chichewa has the same possibility, though without the theoretically important complication of Xhosa introduced by degemination. However, the rule has wider application in Chichewa in another respect: There are more types of noun phrase to which it can apply since Chichewa has greater syncretism of plural markers than Xhosa. Our analysis of Chichewa shows some similarities to the reanalysis of the Xhosa data by Roberts and Wolontis [1974].

The data in question are also comparable to data from Serbo-Croat, and the account given for Serbo-Croat applies in large measure to Chichewa. It will be necessary to give a brief account of resolution in Serbo-Croat in order to demonstrate the relevance of the data. Serbo-Croat is a South Slavonic language spoken in Yugoslavia. It preserves the three Indo-European genders, with distinct agreement markers in singular and plural. The basic gender resolution rules are as follows:

1. If all conjuncts are feminine, the feminine form is used.

2. Otherwise the masculine form is used.

For examples, and for complications which need not concern us here, see Corbett [1983a:187-191]. As can be deduced from these rules (together with the number resolution rule, which specifies the plural), conjoining masculine and feminine, masculine and neuter, feminine and neuter, and even neuter and neuter gives rise to masculine plural agreements. However, and this is the relevant point, if all the confuncts are neuter plural, then neuter plural agreement is required:

(45) ... ta sećanja (neut p1) i razmatranja (neut p1) sve su vise those memories and reflections ever have more

ustupala (neut pl) mesto novim utiscima ... yielded place to new impressions (1.e. made way more and more to new impressions)

(Andrić, Travnička Hronika) 
Since Serbo-Croat has only three genders, the neuter plurals appear as exceptional. Sets of masculine plural or feminine plural conjuncts behave like the singulars and can, at least at first sight, be covered by the ordinary rules.

The analysis offered for the neuter plurals was as follows [Corbett 1983a: 208-209]. We cannot claim that gender resolution rules operate only when the conjuncts are of different genders, since two neuter singulars take a masculine plural verb. Nor can we claim that gender resolution operates only as a consequence of number resolution, since the combination feminine plural plus neuter plural requires a masculine plural verb, which must result from gender resolution. The correct generalization appears to be that gender resolution can be triggered in two ways. First it must operate if number resolution operates. There is a very general principle that if one resolution rule operates, all must operate if possible. ${ }^{7}$ This solution requires a stipulation in the number resolution rule that number resolution can operate only provided there is at least one singular confunct. (This is the restriction mentioned at the beginning of section 4.) The second possible trigger for gender resolution is the presence of different genders in the subject. It can be seen that (45) above meets neither condition: number resolution could not operate, since there is no singular confunct, and gender resolution could not operate without this trigger since the confuncts are of the same gender. It followed as a logical consequence of this analysis that examples with conjoined masculine or conjoined feminine plurals also do not undergo resolution; however, in Serbo-Croat there was no way to prove this claim. In Chichewa, on the other hand, there are two agreement forms ( $i$ and $t i$ ) which are not specified in

${ }^{7}$ There is often the option not to apply the resolution rules and have agreement with one confunct only, typically the nearest, but it is not possible to select from among the resolution rules. Thus, 1st singular and 3rd singular will not produce 3 rd plural, which would result from the operation of number resolution but not of person resolution, agreement in person being with the nearer conjunct. Similarly, masculine plural plus neuter singular will not give rise to masculine singular, by the operation of gender resolution, with agreement in number being with the nearer confunct. 
the output from any of the gender resolution rules and yet, as we have already seen, any of the plural agreement forms can occur, provided each confunct individually would require that form. For Chichewa, more obviously than for Serbo-Croat, the general conditions on the operation of resolution rules are a more economical solution than a long list of individual rules specifying a large number of possible combinations of conjuncts and the required agreement forms.

There are two differences between ChIchewa and Serbo-Croat which are of Importance here. Serbo-Croat has a "parallel" gender system, 1.e. there is a one-to-one mapping of the (three) singular target genders onto the target genders in the plural. Nouns are divided into three controller genders, matchIng the three target genders. As we saw in section 2, the situation in Ch1chewa is considerably more complex. Hence, it makes a difference whether we refer to controller (noun) genders or target genders. Thus, for Chichewa the possible triggers for gender resolution are as follows:

1. Number resolution (number resolution specifies plural agreement; it can operate provided there is at least one singular confunct).

2. The presence of confuncts which would require different target gender forms.

Note that the examples considered at the beginning of this section involving singular conjuncts of the same gender are covered by the first trigger: the presence of a singular confunct triggers number resolution, which dictates the plural; number resolution in turn triggers gender resolution, which specifies $\mathrm{zi}$ - when all confuncts denote nun-humans. The second difference between the two languages is that in the cases of plural conjuncts requiring the same agreement form, resolution is excluded in Serbo-Croat while, as we have seen, it is sometimes an alternative, less favoured, possibility in Chichewa. There Is no unambiguous evidence as to where this option should be stated. One possibility is merely to state that gender resolution may apply optionally even when not obligatorily triggered. An alternative would be the optlonal dropping of the condition on number resolution (hence simplifying that rule); number resolution could then apply even if all confuncts are plural (still spec1- 
fying the plural form of course); it would then trigger gender resolution, which would require the $z i$ form in the examples in question.

We have seen that plural confuncts which require the same agreement form are not normally involved in resolution. Apart from this, Givón's rule requiring the $z i$ form covers many of the examples of conjoined noun phrases denoting non-humans. There are some cases where this form is not felicitous, 8 the most systematic group being examples involving gender 7 . We suggest that this is because gender 7 has a firm semantic basis (the nouns are diminutives), and the resolution rule, itself semantically based, takes no account of this semantic feature. There are two further types of exception to the rules just

8There is a curlous exceptional case, which we leave for future research. It concerns the first gender, which includes humans, several animals, and a very few inanimates. When humans from this gender are conjoined, the agreement marker is a, which is the expected form (as discussed in section 4.2). When, however, noun phrases denoting animals are conjoined, Mtenje still accepts only a :

(1) mphaka ndi galu a-ku-thamanga

$188 \quad 1$ sg ag-pres-run

cat and dog are running

The expected form $z i$ is excluded. However, in constructions in which an object marker for the conjuncts would be required, no acceptable form could be found, $a$, mu, $z i$, and wa all being rejected. When two of the rare inanimates are conjoined, both $a$ and $z l$ are possible.

(11) katundu

ndl kabundula

$\left\{\begin{array}{c}a \\ z i\end{array}\right\}^{-k u-s o w a}$

$188 \quad 188$

plece of baggage and pair of shorts are missing

Though this requires further investigation, it appears that the human/other animate distinction plays a role. Finally, we conjoin noun phrases denoting a human and an inanimate:

(iii) mnyamata ndi katundu

$$
\left\{\begin{array}{r}
a \\
? ? z i
\end{array}\right\}^{-k u-s o w a}
$$

$1 \mathrm{sg}$

198

boy

and plece of baggage

ag-pres-missing

are missing

The fact that a is a marker both of the singular and of the plural for gender 1 nouns is probably at least a part of the explanation for this irregular1ty. And (11i) is likely to involve agreement with mnyamata only (cf. section 4.3). 
given, usually ignored in work on gender resolution. We consider them in subsections 4.1 .1 , and 4.1 .2 .

4.1.1. Gender 10 (infinitives). Studies of gender resolution in Bantu often ignore the question of conjoined infinitives. In other language groups it is frequently the case that conjoined infinitives require neutral agreement (cf. section 3.2.) just as a single infinitive does. However, the fact that Bantu infinitives have a special agreement form and a spectal prefix means that the situation is potentially different, and so worth investigating. The following sentence has conjofned infinftives:

(46) kubvina ndl kuimba $\left\{\begin{array}{l}k u \\ z i\end{array}\right\}$-ku-chitikira uko

to dance and to sing ag-pres-take place there

'dancing and singing are going on there'

Both alternatives, gender 10 agreement and the $z i$ form, are fully acceptable. (Note that this was the case even for the informant who was least ready to accept conjolned structures, querying examples which others immediately found unexceptional.)

There is a semantic difference between the options; given the right context, one of the options can be excluded:

(47) kudya ndi kuyankhula nthawi yomweyo ndi $\left\{\begin{array}{l}\text { kolpa } \\ \star \text { zoipa }\end{array}\right\}^{9}$

to eat and to talk time same is bad

Note the two occurrences of ndi in this example. Ndl with high tone means 'and' (as we have seen in numerous examples) and also 'with'. With low tone,

${ }^{9}$ The adjectival forms kolpa and zolpa are derived as discussed in footnote 4. Kolpa is derived from the verb Ipa :

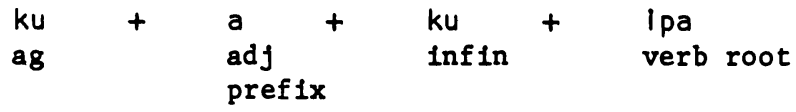

The sequence $a+k u$ undergoes morpheme fusion giving 0 , and the resulting structure $k u+0$ is changed into ko by morpheme final vowel deletion. Zolpa is similarly derived from $z l+a+k u+l p a$. Detalls of these rules and conditions on their application are given in Mtenje [1986:1-50]. 
ndi is the copula 'is'/'are' (which does not take prefixed agreement markers) There is a further ndi which is the first person singular agreement marker; this has low tone, unless high is assigned by a tense marker.

In the next example the $z l$ form is also unacceptable:

(48) kukwatira ndi kumanyenga akazl ena nthawi yomweyo ndi $\left.\begin{array}{c}\text { koipa } \\ \text { zolpa }\end{array}\right\}$
to be married and to flirt women other time same is $\begin{gathered}\text { bad }\end{gathered}$ 'being married and flirting with other women at the same time is bad'

In both these examples, in place of kolpa, we could have chinthu choipa 'a bad thing', but not *zinthu zolpa 'bad things'. The point, of course, is that in both sentences it is doing the two things together which is considered bad.

When it is clear that the actions are considered separately, then the judgements are reversed:

(49) mai a-ku-dwala ndipo kuonera TV ndi kudya ndl mother ag-pres-sick and so to see $\mathrm{TV}$ and to eat are $\left\{\begin{array}{c}\text { zomwe } \\ \text { chomwe }\end{array}\right\}$ a-ku-chita basilo ag-what ag-pres-do only

'mother is sick, and watching TV and eating are the only things she can do'

(50) kuphunzira sukulu ndi kulemera ndi $\left\{\begin{array}{c}\text { zobvuta } \\ \text { *chobvuta }\end{array}\right\}$

to learn school and to be rich are difficult

'being educated and being rich are difficult (to achieve)'

( Zobvuta < $z i+a+k u+$ bvuta ; see footnote 9.) Thus conjolned Infinitives are an exception to the general rule, in that when they are construed as a joint activity the gender 10 form is used; otherwise the $z 1$ form is used as normal. Some examples (11ke (46) above) allow either interpretation.

${ }^{10}$ The forms chomwe and zomwe are derived as follows: to the basic form omwe are added the agreement forms ch $i$ and $z i$. The rule of final vowel deletion referred to in the previous footnote then deletes the $i$ of the agreement markers resulting in chomwe and zomwe respectively. 
It is relatively unusual to conjoin an infinitive with another noun, but when this occurs the regular $z i$ form is used:

(51) kulpa ndi imfa ndi $\left\{\begin{array}{c}\text { zoopsya } \\ * \text { koopsya }\end{array}\right\}$

10

(to be) evil and death are frightening

This example would come under the general rules for inanimates.

4.1.2. Locatives. A related problem, also rarely addressed, is that of conjoined locatives (but cf. Givón [1972:101]). Gender 8, pa 'at', is the most specific in terms of location; it cannot be conjoined even with another gender 8 form:

* panyumba ndi padambo pa-ku-tentha

at house and at marsh ag-pres-be hot

'it is hot at the house and at the marsh'

The alternatives, *mukutentha, *kukutentha, *zikutentha are all excluded. Not surprisingly, when $p a$ is confoined with the other locatives, there is no acceptable form:

(53) munyumba ndi panja $\left\{\begin{array}{l}{ }^{*} \mathrm{pa} \\ { }_{\mathrm{m}} \\ { }_{\mathrm{m}} \mathrm{ku} \\ { }_{\mathrm{z}} \mathrm{i}\end{array}\right\}^{-k u-t e n t h a}$

in house and outside ag-pres-be hot

'it is hot in the house and outside (In the yard)'

(54) kudambo nd panja $\quad\left\{\begin{array}{c}\star p a \\ \star_{\mathrm{mu}} \\ \star_{\mathrm{ku}} \\ { }_{\mathrm{z} i} \mathrm{i}\end{array}\right\}^{-k u-t e n t h a}$

at marsh and at outside ag-pres-be hot

'it is hot at the marsh and outside'

Gender 9, mu 'Inside' allows conjunction with other gender 9 forms:

(55) munyumba ndi mugalaja mu-ku-tentha

in house and in garage ag-pres-hot

'it is hot in the house and in the garage' 
Other agreements, including $z i$, are excluded. Gender 9 will not permit confunction with other genders as shown by (53) above and by (56):

munyumba ndi kunja

$$
\left\{\begin{array}{l}
*_{p a} \\
{ }_{m u} \\
{ }_{k u} \\
{ }_{z} i
\end{array}\right\} \text {-ku-tentha }
$$

in house and at outside ag-pres-be hot

'it is hot in the house and outside'

Gender 10, the least specific of the locatives, also allows conjunction with forms of the same gender:

(57) kudambo ndi kuthengo ku-ku-tentha

at marsh and at bush ag-pres-be hot

'it is hot at the marsh and in the bush'

No other agreement, including $z i$, is acceptable; thus locative gender 10 differs from infinitive gender 10 in this respect. Locative gender 10 cannot be conjoined with other locatives as (54) and (56) show.

We have seen that the locative genders do not follow the general rule for inanimates, since $\mathrm{zi}$ is excluded. Gender 8 does not allow conjoining, 9 and 10 allow conjoining only within the gender. Thus the locative genders, once again, behave differently from the normal noun genders; nevertheless, a full account of the agreement system must include the conditions for conjoining them and the form to be used where conjoining is possible.

4.2. Conjuncts denoting humans. When all conjuncts denote humans, then on the basis of patterns established elsewhere in Bantu, we expect the target gender form used for the plural of gender 1 , that is the form with a in Chichewa. When both nouns are from the first gender then indeed not surprising$1 \mathrm{y}$, the a form is accepted without query:

(58) mkazi ndi mwana a-ku-yenda

$1 \mathrm{sg} \quad 1 \mathrm{sg}$ ag-pres-walk woman and child are walking

Of course, the more interesting cases are those involving at least one noun from a different gender. The following includes a noun from gender 7; again 
three informants had no difficulty in selecting the a form:

(59) mkazi ndi kamwana a-ku-yenda

$1 \mathrm{sg} \quad 7 \mathrm{sg}$ ag-pres-walk

woman and infant are walking

Even with two nouns of gender 7, a is found:

(60) kamkazi ndi kamwana a-ku-gona

$7 \mathrm{sg} \quad 7 \mathrm{sg}$ ag-pres-lie

little woman and infant are lying down

(61) kamkazl ndi tiana a-ku-gona

7 sg $7 \mathrm{pl}$ ag-pres-1ie

little woman and infants are lying down

In both of these sentences Mtenje rejects the $t i$ form (plural of gender 7 ). When both are plural the picture changes:

$$
\begin{array}{lcl}
\text { tlakazl ndi tlana } & t i-k u-g o n a \\
7 \mathrm{p} 1 & 7 \mathrm{p} 1 & \text { ag-pres-1fe }
\end{array}
$$

little women and infants are lying down

Here a was accepted with different degrees of reluctance; $t l$ is considered the normal form. This links immediately to the similar examples involving inanimates; both conjuncts require the same plural gender form and so this is used. The following includes a noun from gender 5:

(63) mkazl ndl mfumu a-ku-yenda

1 sg 5 sg ag-pres-walk

woman and chief are walking

(Note that for Mtenje mfumu could also be plural; some speakers have a plural form mafumu .) While this example is unproblematic, others involving nouns from genders 5 and 6 often prove more difficult:

(64) ??mbala

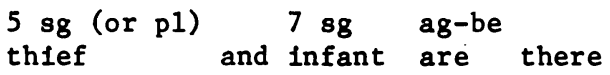

While a is questionable, there is no better alternative. Since nouns in gender 5 have no distinct plural form, we include numerals in the following examples of genders 5 and 6 conjoined: 
(65) mbala $i-\operatorname{modz} i$ ndi chitsilu chi-modzi

$$
\left\{\begin{array}{r}
a \\
? z i
\end{array}\right\}^{-k u-m e n y-a n a}
$$

$5 \mathrm{sg}$ ag-one $6 \mathrm{sg}$ ag-one

ag-pres-hit-recip

'one thief and one fool are fighting'

(66)

mbala $1-\bmod z \mid$ ndi zitsilu zi-tatu $\left\{\begin{array}{c}a \\ ? z i\end{array}\right\}^{-k u-m e n y-a n a}$

$5 \mathrm{sg}$ ag-one $6 \mathrm{pl}$ ag-three ag-pres-hit-rec1p

'one thief and three fools are fighting'

(67) mbala zi-tatu ndl chitsllu chi-modzl $\left\{\begin{array}{c}a \\ ? z i\end{array}\right\}^{-k u-m e n y-a n a}$

$5 \mathrm{pl}$ ag-three $6 \mathrm{pl}$ ag-one ag-pres-hit-reclp

'three thieves and one fool are fighting'

(68) mbala zi-tatu ndi zitsilu zi-tatu $\left\{\begin{array}{c}z l \\ ? ? a\end{array}\right\}^{-k u-m e n y-a n a}$

$5 \mathrm{pl}$ ag-three $6 \mathrm{pl}$ ag-three ag-pres-h1t-reclp

'three thieves and three fools are fighting'

The most obvious point is that, as with non-humans, plural confuncts which would each require the same target agreement marker take that marker (as in (68)); note once again that it is not a question of the nouns themselves belonging to the same controller gender. In all the other examples we find $a$, as expected. But it is surprising that $z i$ is considered to be an alternative, albelt not a favoured one. This option should probably be seen in the light of the data presented in section 3.1, where we saw that semantic agreement with single nouns is a very marginal phenomenon in Chichewa; it is syntactic gender which counts. In conjoined expressions, where the overriding rule is a semantic one (based on the human/non-human distinction), syntactic gender is not totally excluded. The fact that $z l$ is better in (66) than in (65) or (67) is to be explained by the fact that in (66) the conjunct nearer to the verb would require $\mathrm{zl}$.

Summarlzing our discussion of conjolned noun phrases denoting humans, we may say that the situation is not so clear-cut as in some other Bantu languages. Nevertheless, once plural confuncts requiring the same agreement form are left out of account, the basic rule requiring the a form for humans 18 confirmed. 
4.3. Conjuncts denoting humans and non-humans. Givón found that for semantically mixed noun phrases, informants prefer to avoid conjoining the noun phrases and to use the comitative construction instead. If conjoining is forced, however, then the same form as for non-humans is used. In view of the results obtained with plural nouns which require identical agreement forms, it is worth investigating what happens with such nouns when they are semantically mixed. Our first example includes two diminutives, one human and one not:

$\begin{array}{lll}\text { tiana ndi timiphika } & t i-l l \\ 7 \text { pl } & 7 \mathrm{pl} & \text { ag-be }\end{array}$
infants and little pots are there

This sentence was found fully acceptable, while $z i$ was excluded. The same was true of the next example:

(70) anthu ndl abakha $\left\{*_{z i} i\right\}^{-k u-t h a m a n g a}$
$1 \mathrm{p} 1$
$1 \mathrm{p} 1$
ag-pres-run
people and ducks
are running

Though these two examples include nouns of the same gender, this is not required; the requirement once again is that the nouns should be plural and require the same plural target gender agreement marker, as the following example proves:
(71) ana
ndi malalanje a-ku-sowa
$1 \mathrm{p} 1$
$3 \mathrm{p} 1$
ag-pres-missing
children and oranges
are missing

Though of different genders, both take the plural marker $a$ and the sentence is acceptable; $z i$ is totally rejected. The phenomenon is 11lustrated nicely by. this example involving a human noun of gender 5:
(72)
mbala nd
zinth
$z i-1 i$
apo
$5 \mathrm{p} 1$
$6 \mathrm{pl} a g-\mathrm{be}$
thieves and things are there

Recall that nouns of gender 5 do not distinguish number. Mtenje accepted this sentence, but when asked how many thieves were involved, he said that there must be more than one. If imodzi 'one' is added after mbala to 
make it singular, then the sentence is unacceptable, whether $z i$ or $a$ is chosen as the agreement marker.

Other examples involving singular nouns were also rejected:

$$
\begin{array}{ll}
\text { *munthu ndi ng'ombe }^{\text {zi-ku-yenda }} \\
1 \mathrm{sg} & 5 \mathrm{sg} \text { or pl ag-pres-walk } \\
\text { person and cow(s) } & \text { are walking }
\end{array}
$$

A different informant, however, accepted this sentence as unproblematic, irrespective of the number of cows involved (he was the informant who, in general, was most willing to accept conjoined structures). The interesting point about (73) is Mtenje's reaction to the alternative akuyenda. There was some uncertainty at first, but it was considered bad. The use of a gets better if a numeral is included after $n g^{\prime}$ ombe (whether imodzi 'one' or a higher numeral). Consider then the following variant:

(74) munthu ndi ng'ombe zi-tatu a-ku-yenda

$1 \mathrm{sg}$ and $5 \mathrm{pl}$ ag-three ag-pres-wa1k

'a person and three cows are walking'

$\mathrm{Zi}$ is again rejected by Mtenje. The sentence as it stands is accepted or rejected, depending on its interpretation. If the person and the cows are walking separately, then $a$ is also rejected. But if they are together, say the cows are on ropes being pulled along by the person, then a is fully acceptable. The inclusion of a possessive, which favours this type of interpretation, also makes a acceptable:

(75) anthu ndi ng'ombe zawo a-ku-yenda

$1 \mathrm{pl} \quad 5 \mathrm{pl}$ poss ag-pres-wa1k

'the people and their cows are walking'

Now a could be a singular or a plural marker; the crucial example is the following :

(76) chitsilu ndi ng'ombe yake chi-li uko

$6 \mathrm{sg} \quad 5 \mathrm{sg}$ poss ag-be

'the fool and his cow are' there'

The agreement marker chi is unambiguously singular; both $z i$ and a are 
rejected by Mtenje. This example demonstrates that agreement is with the first noun phrase only (and this must also be the analysis for the examples involving a). We might be tempted to think that this is a case of agreement with the first confunct, or "distant" agreement, which is rare but which nevertheless does occur [Corbett 1983b:180]. However, given the data on the interpretations. which make this agreement possible in Chichewa, we must conclude that these examples do not in fact Include conjoined noun phrases. Recall that ndi means both 'and' and 'with'. It appears that in the examples where agreement is with the first noun phrase, ndi should in fact be glossed as 'with'. We are dealing with a comitative construction (and so agreement with the first noun phrase is accepted). Note that the construction is possible without the need to postpose the second noun phrase (for comparable data from Xhosa see Roberts and Wolontis [1974:240-241]).

To sum up our analysis of noun phrases denoting humans and non-humans, we may say that if both are plural and each requires the same plural gender agreement form, that form w1ll be used giving a fully acceptable sentence. In other examples the form $z i$, which was expected to be marginally possible, is in fact excluded (though one informant accepts 1t). Instead the comitative construction is used, in appropriate contexts, though this is not immediately obvious since both noun phrases may st111 stand in front of the verb.

4.4. Summary of gender resolution. The essentials of the strategies for dealing with conjoined noun phrases in Chichewa are as follows:

1. If all conjuncts are plural and require the same plural agreement marker, then this form will be used.

As we saw, this principle operates irrespective of the type of noun involved. In section 4.1 we treated instances of this type as not coming under the jurisdiction of gender resolution (though for some examples gender resolution was a less good alternative). Nevertheless it is surprising that this syntactic principle takes precedence over the semantically based gender resolution rules which follow.

2. If all conjuncts denote humans then the a form w111 be used. 
While there are numerous examples to support this rule, it is not quite straightforward. In section 4.2 we noted several examples (typically involvIng gender 5 nouns) in which the a form was not fully acceptable (though there was no better alternative).

3. If none of the confuncts denotes a human then the $z l$ form w111 be used.

Again this holds for many examples, but there are also except1ons. Nouns from the diminutive gender (gender 7) are problemat1c. Genders 8, 9 and 10 also require special provision as follows:

3a. If Infinitive phrases are confoined and the interpretation is of simultaneous action, then $k u$ will be used; otherwise $z$ as in the matn rule.

3b. Confoined structures involving the locative genders are unacceptable unless all are from gender 9 and the form mu 18 used, or all are from gender 10 and the form $\mathrm{ku}$ is used.

An Interesting point here 1s that though there 18 a single agreement form for gender 10, locatives and Infinitives do not always behave in the same way with regard to agreement. The remaining possibility is the confoining of humans and non-humans:

4. Conjoined structures involving noun phrases denoting humans and nonhumans are unacceptable (unless covered under 1 above). Provided that the comitative interpretation 18 possible, a comitative construction may be used, in which case the head noun phrase controls the agreement. (Other noun phrases are not necessarily postposed.)

5. Conclusion

We have attempted to describe the gender system of one native speaker of Chichewa as a whole, Including phenomena on the fringe of the system, which are often omitted. Th1s approach has considerable advantages. For example, the study of the interrelation between agreement markers which express gender and the genders into which nouns are divided factlitates the analysis of gender resolution. By analysing plural gender markers like $a$ and $z$ as single forms we can make sense of the rule which allows the confolning of some plural noun phrases but not others. 
We have seen that Chichewa has a particularly interesting gender system, espectally in its rules for gender resolution. These do not coincide with any of the sets of rules which have been proposed for other Bantu languages, though there are areas of overlap. Throughout the paper the relevance of the data to typological claims (based on languages within and beyond Bantu) has been amply demonstrated.

\section{REFERENCES}

Bokamba, E.G. 1985. "Verbal agreement as a noncyclic rule in Bantu." In D.L. Goyvaerts (ed.), African Linguistics: Essays in Memory of M.W.K. Semikenke, pp. 9-54. Studies in the Sclences of Language, 6. Amsterdam: Benjamins.

Brauner, S. 1979. "Actuelle Tendenzen der Entwicklung der Konkordanzbeziehungen im Swah1l1." Zeitschrift für Phonet1k Sprachwissenschaft und Kommunikationsforschung 32:422-28.

Comrie, B. 1975. "Polite plurals and predicate agreement." Language 51:406418.

Corbett, G.G. 1979. "The agreement hferarchy." Journal of Linguistics 15: 203-224.

Corbett, G.G. 1980. "Neutral agreement." Quinquereme - New Studies in Modern Languages 3:164-170.

Corbett, G.G. 1983a. Hierarchies, Targets and Controllers: Agreement Patterns in Slavic. London: Croom Helm.

Corbett, G.G. 1983b. "Resolution rules: agreement in person, number and gender." In G. Gazdar, E. Klein and G.K. Pullum (eds.), Order, concord and Constituency, pp. 175-206. Linguistic Models, 4. Dordrecht: Foris.

Corbett, G.G. forthcoming. "The morphology-syntax Interface: evidence from possessive adjectives in Slavonic." To appear in Language 63.

Cornish, F. 1986. Anaphoric Relations in English and French: a Discourse Perspective. London: Croom Helm.

Dalg1sh, G.M. 1976. "Locative NP's, locative suffixes, and grammatical relations." Proceedings of the Second Annual Meeting of the Berkeley Linguistic Society, pp. 139-148. Berkeley: Berkeley Linguistics Soclety, University of California. 
Doke, C.M. 1935. Bantu Linguistic Terminology. London: Longmans, Green and Co.

Givón, T. 1970. "The resolution of gender conflicts in Bantu confunction: When syntax and semantics clash." Papers from the Sixth Regional Meeting, Chicago Linguistic Society, pp. 250-261. Chicago: Chicago Linguist1c Soclety, University of Chicago.

Givón, T. 1972. Studies in ChiBemba and Bantu grammar. Studies in African Linguistics, Supplement 3. Los Angeles: Department of Linguistics and African Studies Center, University of California.

Heine, B. 1982. "African noun class systems." In H. Seller \& C. Lehmann (eds.), Apprehension: Das sprachliche Erfassen von Gegenständen: I: Bereich und Ordnung der Phänomene, pp. 189-216. Tüb1ngen, Gunter Narr.

Horton, A.E. 1949. A Grammar of Luvale. Johannesburg: Witwatersrand University Press.

Laws, R. 1885. Table of Concords and Paradigm of Verb of the Chinyanja Language as spoken at Lake Nyasa. Edinburgh: James Thin.

Mapanje, J. forthcoming. "A case study of agreement phenomena in Bantu." Paper read at the International Seminar concerning current problems of linguistic research in African and Caribbean countries (UNESCO), Paris, September 1985.

Mateene, K. 1980. Essal de grammalre generative et transformationnelle de la langue nyanga. Kinshasa: Presses Universitalres du ZaIre.

Mtenfe, A.D. 1985. "Arguments for an autosegmental analysis of Ch1chewa vowel harmony." Lingua 65:21-52.

Mtenfe, A.D. 1986. "Issues in the nonlinear phonology of Chichewa." Unpub11shed Ph.D. thesis, Untversity College London.

Mtenfe, A.D. forthcoming. "Compensatory lengthening in Chichewa: a nonlinear analy818." To appear in Glossa.

Price, T. 1943. The Elements of Nyanja for English-speaking Students, 2nd edition (first edition 1941). Blantyre, Nyasaland: Church of Central Africa Presbyterian.

Roberts, L. and Wolont1s, M. 1974. "Confunction and concord in Bantu." In E. Voeltz (ed.) Third Annual Conference on African Linguistics, 7-8 Apri1 1972, pp. 231-242. Indiana University Publications, African Ser1es, 7. Bloomington: Research Center for the Language Sclences, Ind1ana University.

Voeltz, E. 1971. "Surface constraints and agreement resolution: some ev1dence from Xhosa." Studies in African Linguistics 2:37-60.

Watkins, M.H. 1937. A Grammar of Chichewa: a Bantu Language of British Central Africa. Philadelphia: Lingulstic Soclety of America. 